\title{
Impressão 3D na Manutenção Industrial e a Redução de
} Custos

Giulia Roberta Rodrigues Camargo
Bacharelado em Tecnologia em Gestão Financeira pela Faculdade de Tecnologia do
Estado de São Paulo - FATEC/Osasco
Analista Comercial

Rua Pedro Rissato, 30. Vila dos Remedios. Osasco/SP. CEP: 06.296-220

E-mail: giulia.roberta@outlook.com

Pedro Augusto Gomes Barbosa

Bacharelado em Tecnologia em Gestão Financeira pela Faculdade de Tecnologia do Estado de São Paulo - FATEC/Osasco

Analista de suporte

Rua Pedro Rissato, 30. Vila dos Remedios. Osasco/SP. CEP: 06.296-220

E-mail: guto91gomes@gmail.com

Fernando de Almeida Santos

Doutorado em Ciências Sociais pela Pontifícia Universidade Católica de São Paulo -

PUC/SP

Professor de Mestrado na Pontifícia Universidade Católica de São Paulo e da FATEC-

Rua Pedro Rissato, 30. Vila dos Remedios. Osasco/SP. CEP: 06.296-220

E-mail: fernando@fernandoasantos.com.br

\section{RESUMO}

Empresas que possuem produções em largas escalas industriais precisam considerar a manutenção de suas máquinas como ponto chave para seu crescimento e desenvolvimento. Nesse sentido, o custo e o tempo para realização da manutenção das máquinas industriais são fundamentais, por isso foi realizada uma pesquisa com tecnologias emergentes que podem otimizar os processos das empresas no quesito de manufatura de peças para troca durante a manutenção das máquinas. Portanto, realizou-se um estudo de caso, com pesquisa qualitativa, sobre uma empresa de grande porte do ramo alimentício que aplica a impressão 3D na manutenção das máquinas da produção de embalagens. A implementação da nova tecnologia obteve resultados positivos que passaram a agregar financeiramente à empresa. A partir deste estudo, conclui-se que a implementação da nova tecnologia é muito vantajosa para médias e grandes empresas que necessitam de trocas de peças rápidas para continuidade de suas produções, dado que a paralisação acarreta em prejuízo ou em retração nos volumes de produção e venda. A impressão 3D ainda é uma tecnologia emergente e pouco difundida no Brasil, mas cresce exponencialmente e atinge diversas áreas que já se beneficiam de sua praticidade e precisão. 
Impressão 3D na Manutenção Industrial e a Redução de Custos

Giulia Roberta Rodrigues Camargo, Pedro Augusto Gomes Barbosa, Fernando de Almeida Santos

Palavras-chave: Manutenção. Impressão 3D. Manufatura. Custos

\section{D printing in industrial maintenance and cost reduction}

\section{ABSTRACT}

Companies with large scale industrial production need to consider the maintenance of their machines as a key point for their growth and development. In this sense, the cost and time to carry out the maintenance of industrial machines are fundamental, that is why a research was carried out with emerging technologies that can optimize the processes of companies in terms of exchange manufacturing parts during the maintenance of the machines. Therefore, a case study was carried out, within a qualitative research perspective in a large company from the food industry that applies $3 \mathrm{D}$ printing in the maintenance of packaging production machines. The implementation of the new technology obtained positive results to the company in financial terms. From this study, it is concluded that the implementation of the new technology is very advantageous for medium and large companies that need the processes to happen in a shorter time so they are able to continue their production with no waste of time, given that each time it stops it faces a loss or retraction in production volumes and sale. 3D printing is still an emerging technology and little used in Brazil, but it grows exponentially and reaches several areas that already benefit from its practicality and precision.

Key Words: Maintenance. 3D Print. Manufacturing. Costs.

Impresión 3D en mantenimiento industrial y reducción de costos

\section{RESUMEN}

Las empresas con producción industrial a gran escala deben considerar el mantenimiento de sus máquinas como un punto clave para su crecimiento y desarrollo. En este sentido, el costo y el tiempo para realizar el mantenimiento de las máquinas industriales son fundamentales, por eso se llevó a cabo una investigación con tecnologías emergentes que pueden optimizar los procesos de las empresas en cuanto a fabricación de piezas para cambio durante el mantenimiento de las máquinas. Por ello, se realizó un caso de estudio, con investigación cualitativa, sobre una gran empresa de la industria alimentaria que aplica la impresión 3D en el mantenimiento de máquinas de producción de envases. La implementación de la nueva tecnología obtuvo resultados positivos que comenzaron a sumar financieramente a la empresa. De este estudio se concluye que la implementación de la nueva tecnología resulta muy ventajosa para las medianas y grandes empresas que necesitan cambios rápidos de 
piezas para continuar su producción, dado que la parálisis provoca pérdida o retracción en los volúmenes de producción y rebaja. La impresión 3D es todavía una tecnología emergente y poco utilizada en Brasil, pero crece exponencialmente y llega a varias áreas que ya se benefician de su practicidad y precisión.

Palabras clave: Mantenimiento. Impresión 3d. Fabricación. Costos.

\section{INTRODUÇÃO}

Atualmente, a exigência imposta sobre as empresas para elevarem seus índices de produtividade e a redução de seus custos é cada vez maior. Neste cenário, é imprescindível que os processos de manutenção nas indústrias acompanhem a evolução da tecnologia a fim de alcançarem resultados positivos nos quesitos citados.

As empresas possuintes de maquinários de grande porte necessitam realizar a manutenção corretiva dos mesmos, portanto, isso objetiva a seguinte problematização: A possibilidade do uso de impressoras 3D para manufaturar as peças usadas nos equipamentos é viável e financeiramente favorável para as empresas?

Conforme a Agência O Globo (2017), devido a necessidade de repor peças que saíram de circulação ou sofreram algum tipo de avaria, testar novas ideias e elaborar protótipos, a utilização da impressão 3D em algumas grandes empresas cresce em ritmo acelerado. De acordo com a Revista Pesquisa FAPESP (2019), um levantamento da consultoria americana Wohler Associates revela que os negócios com impressoras 3D movimentaram US $\$ 5,1$ bilhões no mundo em 2016 e a estimativa é que chegue a $\mathrm{R} \$ 21$ bilhões até 2021.

Esta pesquisa adota como objetivo identificar e avaliar os custos da implementação do processo de impressão 3D para manufatura de peças utilizadas na manutenção de máquinas industriais. Para o desenvolvimento do trabalho foi realizado uma pesquisa qualitativa referente ao cenário da utilização de impressoras 3D e um estudo de caso com uma empresa do ramo alimentício a qual comercializa sorvetes.

O objetivo secundário da pesquisa consiste em demonstrar os gastos existentes na manutenção de máquinas industriais e como a tecnologia emergente da impressão 
3D pode suprir as necessidades das empresas no que se refere à manufatura de peças e à redução de custos.

Agopyan, Souza, Paliari e Andrade (1998) destaca que na produção de um bem ou na prestação de serviços deve-se considerar vários recursos como a mão de obra, materiais e equipamentos que implicam em um custo. A otimização quanto à utilização dos mesmos, visando a redução dos custos é desejável principalmente em se tratando de um mercado globalizado e de competição acirrada, seja para a sobrevivência da empresa e para o aumento da lucratividade na atividade desenvolvida.

Economicamente essa análise é importante porque viabiliza um estudo dos custos relativamente altos de implantação do sistema de impressão 3D e seu rápido retorno do investimento, trazendo como principais benefícios uma economia considerável na compra de peças e otimização de tempo, no que tange a manutenção e emprego de serviços terceirizados.

A análise também aborda a expectativa econômica da tecnologia, evidenciando que o cenário econômico da tecnologia de impressão 3D é otimista e possui oportunidades no mercado para ser explorada e alcançar um crescimento exponencial, ainda que o Brasil possua apenas cerca de $2 \%$ do total dos negócios. Além disso, a impressão 3D viabiliza para as fábricas o afastamento dos polos industriais e a aproximação dos centros consumidores, aumentando as chances de maior comercialização e demanda.

Vizzotto, Motta e Camargo (2019) destacam que quando a Gestão Estratégica de Custos (GEC) está alinhada com a estratégia da empresa as organizações tendem a apresentar um maior desempenho.

Desse modo, pelo fato da análise e redução de custos ser um aspecto estratégico, em especial em um ambiente de alta tecnologia e de muita competividade, despertou-se o interesse por esta pesquisa. Portanto, a sua contribuição é possibilitar uma análise que pode ser considerada para tomada de decisões de empresas de diferentes portes. 
O artigo apresenta o referencial teórico, composto por três temáticas. Inicialmente aborda a inovação, fator que despertou o interesse pela pesquisa. $O$ segundo tema debatido é a relevância de reduzir custos em um ambiente competitivo. Ao final explana o desenvolvimento e a finalidade da impressão 3D.

$\mathrm{Na}$ metodologia, apresentada posteriormente, estão destacadas as etapas para elaboração do estudo. A terceira parte consiste no estudo de caso, sendo descrita a forma como se realiza a impressão 3D na manutenção industrial, além de contemplar a análise financeira.

\section{REFERENCIAL TEÓRICO}

\subsection{Inovação}

O cenário econômico atual e as mudanças constantes que ocorrem, no que tange à tecnologia, exigem que as empresas se atualizem e acompanhem a evolução para que não estejam em desvantagem competitiva.

Del Val (2016) considera que o segmento da produção industrial até o momento já enfrentou três revoluções que transformaram e impactaram o modelo de negócio trazendo consigo uma grande evolução econômica para as empresas. A primeira revolução em meados dos anos XVIII e XIX, pois, mecanizou os processos de produção, principalmente agrária e artesanal, além de aprimorar as máquinas a vapor. A segunda revolução apresentou um novo modelo de produção em série e em massa, surgindo as fábricas, que passaram a utilizar o aço e a energia elétrica. Já a terceira revolução avançou nos sistemas computadorizados e robóticos para manufatura.

Roblek, Mesko e Krapez (2016) discorre que em 2011 destaca na Alemanha um novo conceito conhecido como indústria 4.0, um propósito de desenvolvimento da política econômica alemã, que marca o período pela automação dos processos com o uso das tecnologias na manufatura.

Borlido (2017), por sua vez, considera que o novo modelo inclui como base, tecnologias como a Internet das Coisas (IoT), uma rede pela qual as máquinas 
conseguem se comunicar via internet, não somente a comunicação, como também o compartilhamento de informações e dados para o desenvolvimento e conclusão de diversas tarefas e, além dessa tecnologia, há evolução na impressão 3D que já existia há quase três décadas, com muitas restrições de acesso para as indústrias.

Segundo Hammer, Kostroch e Quiros (2017), a indústria 4.0 abrange muitas vertentes da tecnologia, além da Internet das Coisas (IoT) e a impressão 3D (Manufatura aditiva), pois existe o Big Data que se trata de uma captação de dados e análise dos mesmos, transformando-os em informações de qualidade para a empresa, além de existirem as tecnologias como a computação em nuvem, a segurança cibernética e a realidade aumentada.

A computação em nuvem (Cloud Computing), segundo Silva (2017), auxilia na redução de custos operacionais, tais como o alto investimento na compra de hardware e software, datacenters locais e especialistas para gerenciamento da infraestrutura. Essa tecnologia atua como solução tecnológica para armazenamento, banco de dados, redes e softwares que passam a ser realizados e salvos pela internet, sendo possível atender exatamente a necessidade da empresa e modificar conforme a demanda, aumentando ou diminuindo.

A segurança cibernética possui conexão direta com a computação em nuvem, pois trata-se de um conjunto de práticas que protegem informações armazenadas e que são transmitidas por meio de comunicação como a internet. Por fim, a realidade aumentada trata-se de uma tecnologia que permite a mistura do mundo real com o ambiente virtual por sensores de movimento, câmeras etc.

De acordo com Yang Lu (2017), para a utilização das tecnologias trazidas pela nova revolução industrial, existem alguns princípios em que se baseia:

- Interoperabilidade: habilidade de dois sistemas se comunicarem e utilizarem suas funcionalidades com a finalidade de um resultado final positivo;

- Virtualização: desmaterializar os processos que antes eram físicos e passam a ser virtuais (de preferência com a tecnologia Cloud); 
- Descentralização: aumento da capacidade de descentralizar atividades, mantendo a mesma eficiência;

- Capacidade em tempo real: resolução de assuntos e problemas em tempo real, dado a facilidade em ter acesso às informações;

- Orientação para o serviço: maior capacidade de foco no serviço e no cliente (ou utilizadores do sistema);

- Modularidade: processos e tarefas mais flexíveis.

Roblek, Mesko e Krapez (2016), também afirmam que em relação às indústrias, um dos conceitos utilizados na indústria 4.0 é "Smart Factory" (Fábrica Inteligente), a qual traz um novo modelo para a fábrica, tornando-se mais inteligente, independente e com melhorias contínuas nos processos internos. Uma fábrica inteligente trabalha com máxima eficiência e com mais qualidade na produção dos produtos, aumentando também sua produtividade. Também é abordado o conceito "Smart Maintenance" (Manutenção Inteligente) que discorre sobre os níveis e tipos de manutenção e sobre os sistemas que devem ser desenvolvidos e aptos para a captação e tratamento de dados dos processos internos a fim de melhorar o controle sobre a manutenção industrial.

\subsection{Importância em reduzir custos em ambiente competitivo}

Como citado na introdução, a gestão estratégica de custos é relevante principalmente no mercado atual. Oliveira, Perez e Silva (2015) destacam que, tradicionalmente, a análise de custos é conhecida e praticada como o processo de avaliação do impacto financeiro das decisões gerenciais alternativas.

Martins (1998) destaca que um compromisso muito forte na contabilidade estratégica é devido ao longo prazo, pois há a obrigação de começar a introduzir indicadores, procurar identificar quais são, implantar acompanhamento para verificar as aderências da empresa com relação ao seu plano estratégico e uma ampliação muito forte para que passem a agregar informações, além das monetárias, as físicas, de produtividade e de qualidade, que são amplamente subjetivas. 
Oliveira, Perez e Silva (2015) consideram que a gestão estratégica de custos deve ser vista, compreendida e praticada em um contexto mais amplo, em que os elementos estratégicos tornam-se mais conscientes, explícitos e inseridos nos procedimentos da controladoria e da contabilidade de custos.

Em relação à gestão estratégica de custos, Trajano, Welter, Souza e Schmidt (2018) destaca que diante da concentração de empresas disputando mercado entre si, faz-se necessário, cada vez mais, a elaboração de estratégias perspicazes perante a concorrência acirrada.

Logo, para ambientes competitivos é muito relevante o controle e a redução de custos.

Kardec e Nascif (2001) consideram que a competitividade no mercado e a rápida evolução tecnológica em indústrias são causas que justificam o investimento das empresas em altos padrões de tecnologia, além de auxiliar e melhorar seus processos. Nesse sentido, as empresas buscam melhorias na produção, redução de custos e de tempo, de maneira que as tornem mais competitivas devido à qualidade e produtividade de seus produtos, processos e serviços.

Na concepção de Pinheiro (2007), uma organização ganha vantagem se conseguir executar suas atividades com menor custo ou com melhor qualidade, comparada à concorrência. Nesse caso, as vantagens competitivas apresentadas são a liderança em custos e a diferenciação dos produtos. Porter (1986) acredita que além dessas duas vantagens, também deve-se salientar a focalização ou o enfoque.

A estratégia de liderança em custos é onde a empresa oferece um menor custo aos seus clientes na produção de produtos ou na prestação de serviços. Uma grande forma de se obter essa vantagem, na visão de Bruni e Famá (2009), é por meio da curva de aprendizagem onde o custo diminui na medida em que a experiência de se fazer determinada tarefa aumenta, podendo o produto ou serviço ser oferecido por um preço abaixo da concorrência. Além de eficiência da mão de obra obtida pela curva de aprendizagem, os autores, ainda, destacam que a substituição de insumos e melhores 
métodos de fabricação são muito eficientes para diminuir os custos, podendo oferecer um bem ou serviço mais acessível.

De acordo com Rocha (1999), a expressão vantagem competitiva designa a situação ou o estado em que as empresas conseguem obter recursos em melhores condições de preço, qualidade, quantidade e prazos em relação aos concorrentes.

Segundo Porter (1986), existem três estratégias genéricas que as empresas podem utilizar para obter vantagem competitiva: liderança de custo atuando com preços mais baixos no mercado; estratégia de diferenciação, diferenciando o produto e ofertando exclusividade ao cliente e a estratégia de enfoque, ou seja, encontrar um nicho de mercado, no qual seja possível competir de maneira favorável.

A liderança de custos sempre foi uma das estratégias utilizadas pelas empresas para obtenção da vantagem competitiva. Durante muito tempo o gerenciamento de custo concentrou-se no processo produtivo e foi utilizado como base para fixação do preço de venda. O custo-padrão era o principal instrumento de controle e gerenciamento dos custos.

Porter (1986) afirma que estudos de custos costumam concentrar-se nos custos de fabricação, muitas vezes negligenciando o impacto de outras atividades, como marketing, serviço e infraestrutura sobre a posição dos custos relativos. Além disso, o custo de atividades industriais é analisado em sequência, sem reconhecer os elos entre atividades que podem afetar os custos.

Como resposta à essa negligencia, as empresas têm utilizado amplamente o custeio meta para a gestão dos custos em substituição ao custo padrão, por ser um método voltado ao mercado e por considerar todas as fases do produto. Esse custo desejado precisa ser alcançado para que a empresa atinja o lucro desejado. Enfim, esse sistema de custeio possui um potencial de informações que ajudam à tomada de decisões de forma rápida e acurada em todos os níveis organizacionais operacional tático e estratégico. 
Groover (2007) considera que a manutenção industrial busca na impressão 3D uma possível substituição de métodos tradicionais de manutenção e se dá pelo fato de que torna possível produzir peças de elevada competitividade e de forma rápida.

Desse modo, a manutenção pode ser vista como ferramenta de estratégia das empresas, dado que é por meio desse processo que indicadores importantes da produção como a disponibilidade das máquinas e capacidade produtiva podem influenciar diretamente no resultado financeiro.

Segundo Moro e Auras (2007), é importante estabelecer um programa de manutenção estruturado a fim de evitar grandes prejuízos para a empresa com equipamentos parados por um longo período para manutenção corretiva, provocando diminuição ou interrupção da produção, atrasos nas entregas, aumento de custos, pois essas consequências podem levar a perdas financeiras e a insatisfação de clientes.

De acordo com Horne e Hausman (2014), a técnica de modelagem tridimensional permite a impressão de peças e produtos personalizados e que atendem à necessidade da empresa ou do cliente. No que se refere à produção de peças, é possível produzir em pequenas escalas segundo a necessidade da empresa, além de ser realizado em menor tempo e com custos menores.

Moro e Auras (2007) afirmam que, após um longo período no qual as indústrias utilizaram o sistema de manutenção corretiva e causaram desperdícios e retrabalho, surge um sistema de gerenciamento que proporciona eficiência, a TPM (Total Productive Maintenance). A TPM possui cinco pilares que ajudam a empresa a aumentar a disponibilidade das máquinas, reduz a zero as falhas e aumenta consequentemente a lucratividade, são eles:

- a eficiência, ou seja, prática de atividades que melhoram a produtividade do equipamento;

- o autorreparo, isto é, possuir sistemas de manutenção autônomos, executados pelos operadores do equipamento;

- o planejamento de manutenção que proporciona uma organização e estar preparada para qualquer possível falha no sistema; 
- programa de manutenção preventiva contínuo;

- treinamentos para capacitar as equipes, aumentar as habilidades e rendimento;

- ciclo de vida da manutenção, gerenciando completamente os equipamentos.

Desse modo, segundo Vaz (1998), a manutenção contribui para aumento da produtividade, mas para que isso ocorra efetivamente é preciso que a empresa possua uma gestão realizada com visão estratégica.

\subsection{Impressão 3D}

Gorni (2003) reconhece a impressão 3D como uma forma de tecnologia de fabricação aditiva, onde um modelo tridimensional é criado por sucessivas camadas de material. São geralmente mais rápidas e mais fáceis de se usar do que outras tecnologias de fabricação aditiva. Também, denominada de fabricação aditiva, o processo de criação de objetos a partir de modelos digitais criados em três dimensões e as tecnologias de fabricação são: fusão a laser, fundição a vácuo e moldagem por injeção. A impressão 3D funciona de forma semelhante à impressão bidimensional, a diferença encontra-se no formato do arquivo digital a ser enviado à impressora, que geralmente é um arquivo CAD e os materiais utilizados.

Duarte (2014) afirma que a tecnologia precursora da impressão 3D é a estereolitografia, sendo um dos métodos mais detalhados de prototipagem rápida e criada em 1984 pelo engenheiro físico norte-americano Chuck Hull. Alguns anos depois, Chuck fundou a 3D Systems Corp., patenteando sua criação e iniciando a comercialização da tecnologia.

A partir dos anos 80, a evolução da tecnologia avançou e nos últimos anos a tecnologia da impressão 3D vem recebendo cada vez mais atenção das empresas e empreendedores, devido à sua possibilidade de criação, inovação e soluções rápidas, além de relativamente baratas. 
Com o passar dos anos, houve marcos recorrentes à essa tecnologia, que comprovam sua evolução, importância e espaço que vem adquirindo. Em 2010, desenvolveu-se o primeiro protótipo de carro impresso, chamado de Urbee; em 2011, a Universidade de Cornell começa a desenvolver uma impressora 3D para comidas, em 2012, realizou-se a impressão da primeira mandíbula protética que foi implantada em 2013. Em 2014, o presidente Obama menciona a tecnologia de Impressão 3D em um discurso da União e, em 2015, a Carbon 3D lança sua revolucionária máquina de impressão CLIP 3D ultra rápida.

Conforme a Figura 1, identifica-se recentes e relevantes pesquisas e desenvolvimentos da impressão 3D:

\begin{tabular}{l|c}
\multicolumn{1}{c|}{ Fonte } & Objetivo da Pesquisa \\
\hline $\begin{array}{l}\text { Varaprasada Rao Manda, Vidhu Kampurath, Chaitanya } \\
\text { Msrk (2018) - 3D Printing and its Effect on Outsourcing: A } \\
\text { Study of the Indian Aircraft Industry. }\end{array}$ & $\begin{array}{c}\text { Uso da impressão 3D na indústria de } \\
\text { aeronaves. }\end{array}$ \\
\hline $\begin{array}{l}\text { Eduardo Gomes, Ricardo Dias, Bruno Rocha, Jose } \\
\text { Santiago, Fabricio Dinato, Eduardo Saadi, Walter Gomes, } \\
\text { Fabio Jatene (2018) - Use of 3D Printing in Preoperative } \\
\text { Planning and Training for Aortic Endovascular Repair and } \\
\text { Aortic Valve Disease. }\end{array}$ & $\begin{array}{c}\text { Protótipos feitos por Impressão 3D a } \\
\text { serem usados em cirurgias } \\
\text { cardiovasculares. }\end{array}$ \\
\hline $\begin{array}{l}\text { Jaebum Son, Diana Valenzuela, Maria Gutierrez, Paola } \\
\text { Castellanos (2017) - An Update on Orthopedic Applications } \\
\text { Using 3-Dimensional Printing Technologies. }\end{array}$ & $\begin{array}{c}\text { Impressão 3D a ser usada na área de } \\
\text { Ortopedia para próteses. }\end{array}$ \\
\hline $\begin{array}{l}\text { Rodrigo Kormann, Ricardo Morschbacher, Hamilton Moreira } \\
\text { e Patricia Akaishi (2018). }\end{array}$ & $\begin{array}{c}\text { Implante de resina fotocurável para } \\
\text { evisceração produzido por impressora } \\
\text { tridimensional. }\end{array}$ \\
\hline
\end{tabular}

Figura 1. Pesquisas recentes sobre impressão 3D

Fonte: Elaborado pelos autores. 


\section{METODOLOGIA}

A metodologia deste trabalho é baseada em uma pesquisa objetiva e um estudo de caso através de uma empresa que atua no ramo de alimentos, evidenciando por meio de uma análise financeira os benefícios da manutenção de máquinas industriais, utilizando-se a impressão 3D, em termos de redução de custos, otimização de tempo e até mesmo inovação.

O trabalho foi realizado conforme as etapas apresentadas na Figura 2:

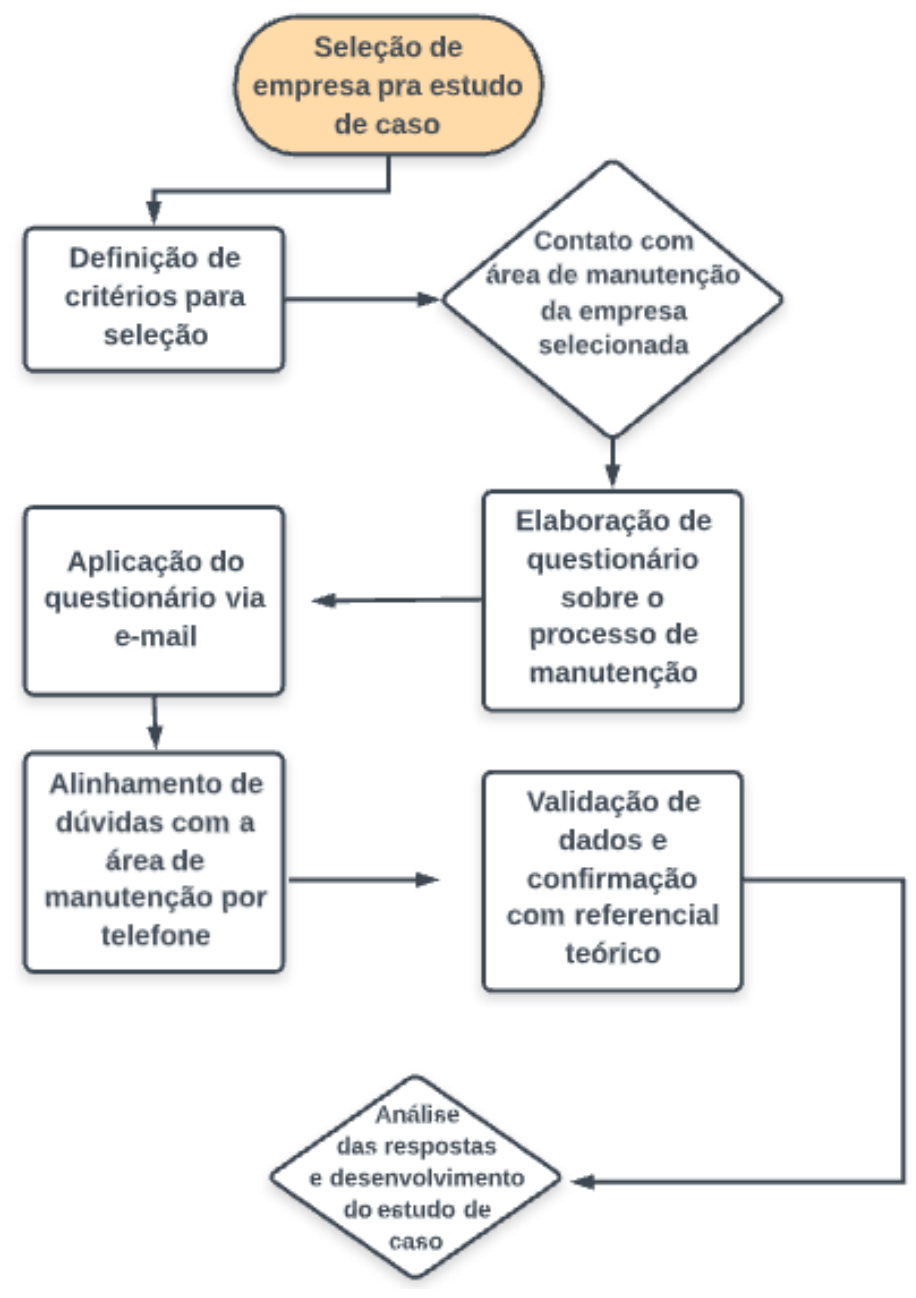

Figura 2. Fluxograma da metodologia da pesquisa

Fonte: Elaborado pelos autores. 
Para a seleção da empresa do estudo de caso foram realizadas buscas em lojas que comercializam impressoras 3D e insumos para a impressão. A pesquisa foi feita baseada nos seguintes critérios:

- o processo de manutenção das máquinas industriais devem ser mais de $50 \%$ com a utilização da impressora 3D;

- a utilização da impressão 3D na manutenção das peças das máquinas deve reduzir os custos de maneira relevante para a empresa;

- o processo da impressão e acabamento das peças não deve demorar mais que 24 horas.

A empresa a qual atendeu a todos os critérios citados atua no ramo alimentício comercializando sorvetes de palito e em pote. O contato foi fornecido por uma loja que comercializa para essa empresa insumos para a impressão das peças.

Para apuração e análise da redução de custos com a implementação da impressão 3D no processo de manutenção das máquinas, aplicaram-se questionários com perguntas técnicas sobre a impressora utilizada, dados financeiros e sobre a capacidade produtiva a fim de serem utilizados em cálculos de acompanhamento da manutenção industrial e de custos.

Neste trabalho, realiza-se a apresentação do processo de manutenção das máquinas com a impressão 3D e seu custo-benefício. São utilizados como fonte de estudos os dados disponibilizados por uma empresa do ramo alimentício, comerciante de sorvetes, por meio de um questionário de perguntas abertas e elaboradas com base no referencial teórico deste artigo e ainda com foco nos custos e na redução dos mesmos para a empresa. Dessa forma, as perguntas abordavam sobre o processo da impressão das peças, o custo de sua instalação, manutenção, durabilidade e rentabilidade.

A análise financeira realizada para apuração do resultado do investimento total é feita com base nos dados fornecidos no questionário aplicado e a pesquisa consiste em analisar e apresentar um novo modelo para a manutenção de máquinas industriais de maneira eficiente e econômica. 
Como métrica, deu-se ênfase nos custos totais de investimento para a aquisição da máquina e adaptação ao novo modelo de manutenção, além do retorno sobre o valor investido. Também, realizou-se uma projeção da economia que se obtém com base nos dados fornecidos.

De acordo com os dados levantados, por meio do questionário aplicado com a empresa escolhida, elaborou-se um comparativo entre o processo antigo e o novo, utilizando a tecnologia da impressão 3D. Esse comparativo tem como objetivo demonstrar as diferenças de custos para a empresa na manufatura de peças, levando em consideração insumos, mão de obra, tempo de manutenção e custos.

Os dados foram obtidos por um funcionário da empresa responsável pelo setor de manutenção, o qual cedeu as informações necessárias para o desenvolvimento do trabalho. A empresa em questão solicitou que seu nome fosse ocultado por razões de mercado.

Os valores de custos utilizados nos cálculos foram disponibilizados por meio do questionário aplicado ao supervisor da área de manutenção, sendo informados custos de investimento da implementação, custos para impressão das peças em comparação aos custos das peças que eram adquiridas, por meio de um fornecedor regional.

Para cálculo da redução de custos, é realizada uma comparação do custo total anterior para troca de uma peça específica versus o custo total atual para impressão da peça. Além disso, utilizaram-se métricas de manutenção industrial, tais como a disponibilidade das máquinas, ou seja, quanto tempo a produção é mantida sem pausas ou reduções na capacidade produtiva e o MTTR (Mean Time To Repair) que considera quanto tempo é necessário para o reparo da máquina a cada manutenção realizada. 


\section{ESTUDO DE CASO}

\subsection{Impressão 3D na manutenção industrial}

O processo de manutenção industrial com a impressão 3D é embrionário no setor responsável e se iniciou em maio de 2018. Neste estudo de caso, o processo é realizado com a impressora da marca AE3D, fabricante localizado no interior de São Paulo. A empresa do estudo optou por um fabricante regional a fim de incentivar a indústria nacional e facilitar possíveis processos de assistência, caso fosse necessário.

A manutenção das máquinas com a utilização da impressora é realizada após um estudo pela equipe responsável sobre as peças que possivelmente podem ser substituídas por materiais compatíveis e similares. Após o estudo, são realizados alguns testes de resistência com as peças impressas e colocadas na linha de produção com o intuito de testar sua durabilidade máxima.

Após a identificação das peças na linha de produção, é realizado o escaneamento das mesmas, e então, passam por mínimos ajustes quando necessário em um software especializado, o "Simplify3D". Não é necessária nenhuma formação técnica para operar a máquina, apenas conhecimentos básicos de informática.

Conforme as Figuras 3 e 4, as peças manufaturadas por meio da impressora 3D se assemelham muito à peça original do fabricante e possuem resistência similar de acordo com o material utilizado na impressão. 

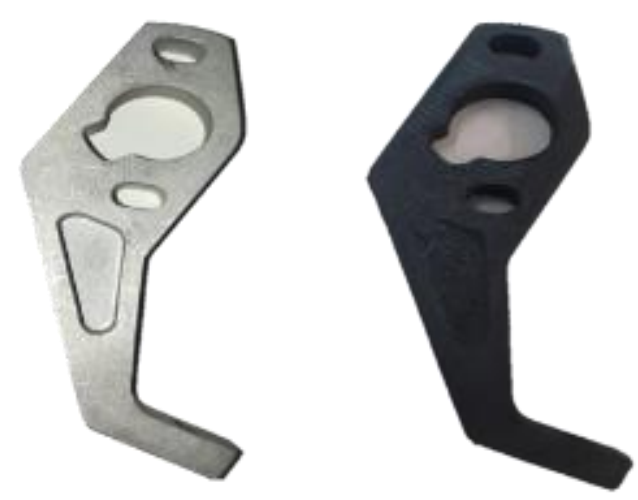

Figura 3. Comparativo entre peça original (à esquerda) e peça produzida por impressão 3D (à direita)

Fonte: Empresa contatada para o estudo de caso.

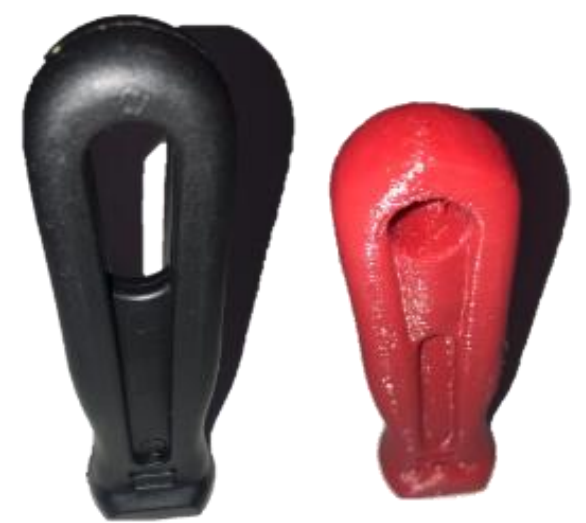

Figura 4. Comparativo entre peça original (à direita) e peça produzida por impressão 3D (à esquerda).

Fonte: Empresa contatada para o estudo de caso.

A impressora possui a possibilidade de impressão nos materiais ABS, PLA, PETG, Flexível, Tritan, PVA e Nylon e não é necessário adquirir o filamento (matériaprima) de um fornecedor específico.

O consumo de energia elétrica da impressora é de 0,25 kw/h e segundo dados do resumo executivo de Energia Elétrica do Governo do Estado de São Paulo (2019), a taxa por kw/h consumido cobrado pela cessionária de energia da região de Valinhos é de $\mathrm{R} \$$ 
0,578 para comércios e indústrias que utilizam mais de $100 \mathrm{kw} / \mathrm{h}$ e se enquadram na utilização nível bandeira vermelha. Considerando o cenário realista a impressora é utilizada em média 4 vezes ao mês, durante 6 horas, para cada para impressão da peça, dessa maneira conclui-se que o valor total do consumo mensal da impressora é de $R \$$ 13,87. Para esse cálculo não foi considerada a taxa $R \$ 6,00$ a cada $100 \mathrm{kw} / \mathrm{h}$ utilizados pela indústria.

Em relação à instalação da impressora, basta uma mesa ou bancada firme e uma tomada com energia $110 \mathrm{~V}$ ou $220 \mathrm{~V}$.

\subsection{Análise financeira}

Para análise financeira do estudo de caso são utilizados os valores do investimento inicial na impressora $3 \mathrm{D}$ e os custos de impressão de cada peça manufaturada.

A produção da empresa do estudo é de potes de sorvetes que possui fábrica no interior de São Paulo. A mesma possui três esteiras de produção com suas máquinas, duas com $100 \%$ da produção em potes grandes e uma com $80 \%$ da produção em potes tamanho $\mathrm{G}$ e $20 \%$ em potes tamanho $\mathrm{P}$. As máquinas operam 6 dias por semana e 24 horas por dia com operadores que revezam em turnos, totalizando em média 28 dias de produção ao mês.

As máquinas têm capacidade produtiva média diária de aproximadamente 310 mil potes, totalizando uma produção mensal de quase 9 milhões de potes com preço médio de venda a $R \$ 18,00$ reais. Ou seja, a venda mensal se aproxima de 160 milhões de reais com distribuição por todo o país.

Dado que as máquinas operam 24 horas por dia e 6 dias por semana, faz-se necessária a manutenção preventiva e corretiva. Desde maio de 2018, a empresa optou por implementar em seu processo de manutenção a impressão 3D, a qual poderia manufaturar as peças as quais corriqueiramente quebravam devido seu uso constante.

Antes da implementação do processo adicional de manutenção, por meio da impressora, as peças que precisavam ser trocadas eram compradas de um fornecedor 
regional e demoravam em média 7 dias para serem entregues e posteriormente realizada a manutenção na máquina. O setor responsável pela manutenção das máquinas adquiria um kit de peças das máquinas comercializado pelo valor aproximado de $R \$ 1.336,00$ reais e continha algumas peças, tais como: uma placa, uma base, duas válvulas e uma tampa.

A companhia necessita de um controle de estoque para peças que historicamente demandam a troca constante para evitar que as máquinas fiquem fora de operação. Em casos de falta de estoque das peças necessárias para troca, a máquina opera parcialmente, diminuindo a capacidade produtiva de potes ou em alguns casos não opera, cessando uma das linhas de produção.

Dado que o prazo médio para entrega das peças solicitadas ao fornecedor e o reparo nas máquinas é de 7 dias, caso fosse necessário suspender ou diminuir a produção dos potes, é possível reduzir até 2 milhões de potes na produção, ou seja, quase $25 \%$ da produção mensal.

Com a possível manufatura das peças e o processo de escaneamento e impressão das mesmas, o tempo de reparo da máquina foi reduzido no máximo 1 dia (6 horas para a preparação, impressão da peça a ser substituída e o reparo na máquina). Ou seja, caso seja necessária a suspensão ou redução no processo produtivo dos potes, o número máximo de potes a serem reduzidos é de até 314 mil, representando apenas $4 \%$ da produção mensal, conforme Tabela 1.

Tabela 1

Comparativo do impacto na produção da empresa entre a espera do fornecimento de peças e a utilização da impressão 3D para manufatura das mesmas.

\begin{tabular}{ccc}
\hline Descrição & Quantidade de potes & $\%$ \\
\hline Impacto na produção (7 dias) & 2.196 .250 & $25 \%$ \\
Impacto na produção (1 dia) & 313.750 & $4 \%$ \\
Delta & $\mathbf{1 . 8 8 2 . 5 0 0}$ & $\mathbf{2 1 \%}$ \\
\hline
\end{tabular}

Nota. Fonte: Dados da pesquisa. 
Conforme citado no tópico 4.1, o processo da impressão 3D exige equipamentos e insumos para que seja realizado o processo da manufatura, os quais possuem custos relativamente baixos. $O$ investimento inicial da impressora $3 D$ + escâner foi de $R \$$ $39.000,00$ reais à vista, enquanto os insumos possuem custos entre $R \$ 1,00$ a 45,00 reais para produção por peça, conforme Tabela 2:

Tabela 2

Valores dos custos de insumos e energia utilizados na impressora 3D.

\begin{tabular}{cc}
\hline Custos Diretos + Indiretos & Custo \\
\hline PLA + Fibra de carbono & $\mathrm{R} \$ 45,00$ \\
Lixa + Cola & $\mathrm{R} \$ 1,28$ \\
Energia elétrica & $\mathrm{R} \$ 3,45$ \\
Total & $\mathbf{R} \$ \mathbf{4 9 , 7 3}$ \\
\hline
\end{tabular}

Nota. Fonte: Dados da pesquisa.

O custo da manufatura por peça substituída é de aproximadamente $R \$ 50,00$ reais, enquanto antes a empresa precisava adquirir o kit de peças por $R \$ 1.336,00$ reais, o qual continha diversas peças incluindo as que precisavam ser substituídas. As peças do maquinário não são comercializadas individualmente, o que dificulta a substituição das peças e manutenção das máquinas. Em geral, a economia da empresa por peça trocada chega a $96 \%$ por peça conforme Tabela 3: 
Impressão 3D na Manutenção Industrial e a Redução de Custos

Giulia Roberta Rodrigues Camargo, Pedro Augusto Gomes Barbosa, Fernando de Almeida Santos

Tabela 3

Comparativo de valores entre kit de peças compradas e peça manufaturada individualmente pela impressora 3D.

\begin{tabular}{cc}
\hline Descrição & Custo por peça \\
\hline Antes da impressora & $\mathrm{R} \$ 1.336,00$ \\
Após a impressora & $\mathrm{R} \$ 49,73$ \\
Economia $(\mathrm{R} \$)$ & $\mathrm{R} \$ 1.286,28$ \\
Economia (\%) & $\mathbf{9 6 , 2 8 \%}$ \\
\hline
\end{tabular}

Nota. Fonte: Dados da pesquisa.

Outra métrica analisada neste estudo é o tempo do retorno sobre o investimento na tecnologia de impressão 3D, dado que o investimento inicial foi de $\mathrm{R} \$ 39.000,00$ reais e que todos os meses o setor de manutenção despendia cerca de $R \$ 1.300,00$ reais a cada kit comprado, sendo a média de 4 kits comprados por mês, o total gasto por mês era de cerca de $R \$ 5.200,00$ reais. Com a impressão de peças no próprio setor, dado que a impressão de cada peça custa aproximadamente $R \$ 50,00$ reais, o custo total cai para apenas $R \$ 200,00$ reais mensais. O delta de $R \$ 5.000,00$ reais entre o custo anterior e o atual cobre o investimento na compra da impressora após o acumulado em 8 meses, totalizando $R \$ 40.000,00$ reais de economia.

Como métrica de acompanhamento na gestão de manutenção industrial segundo o site Engeman, calcula-se a disponibilidade do maquinário, que após a implementação da impressão 3D aumentou de $80 \%$ para $99 \%$. Para cálculo da disponibilidade, há o MTTR (Mean time to repair) de ambos períodos, antes e depois da implementação. Antes da impressão 3D, as máquinas em média tinham média de tempo de reparo de 42 horas, atualmente possuem cerca de 1 hora apenas, o que eleva a disponibilidade das máquinas na linha de produção.

Hausman e Horne (2014) destacam como uma das vantagens da impressora 3D a economia em escala, permitindo a criação de itens individuais com menor tempo e custo, além de reduzir os materiais utilizados e funcionários para operação do processo de manutenção. 
Nos resultados, destaca-se a possibilidade de personalização das peças que são compatíveis com os materiais de impressão, permitindo que a empresa tenha flexibilidade para imprimir o que tiver de necessidade. De acordo com Canessa, Fonda, e Zennaro (2013), um dos maiores benefícios da impressão 3D é a redução de custos e no estudo de caso é possível verificar uma redução de mais que $90 \%$ na manutenção de algumas peças nas máquinas industriais.

Desse modo, pode-se concluir que a impressão 3D para manutenção industrial é benéfica e pode gerar resultados positivos em relação ao caixa da empresa.

A economia citada, associada a mesma qualidade, pode ser considerada uma vantagem competitiva, pois, conforme destaca Martins (1998), a Contabilidade Estratégica de Custos deve considerar diversos aspectos. Destaca-se que tal vantagem, como pode ser observado pelo caso analisado, contribui para alinhar os controles de custos à estratégia da empresa, fato que contribui ao melhor desempenho, segundo Vizzotto, Motta e Camargo (2019).

\section{CONSIDERAÇÕES FINAIS}

Com a constante evolução da tecnologia e novas técnicas de manufatura, o uso da emergente Impressora 3D para produção de peças usadas nos equipamentos vem sendo aplicada em algumas empresas, e o custo e viabilidade de sua implementação foram questionadas neste estudo de caso.

De acordo com as pesquisas e o estudo de caso realizados foi possível afirmar que o processo da impressão 3D exige equipamentos e insumos que possuem custos muito baixos. O investimento inicial da impressora 3D, com o escâner foi de $R \$$ $39.000,00$ reais à vista enquanto os insumos possuem custos entre $R \$ 5,00$ a $R \$ 45,00$ reais.

Também houve uma grande diferença de custos, pois antigamente a empresa era obrigada a adquirir um kit de peças por $R \$ 1.300,00$ reais, para suprir a necessidade de troca de apenas algumas peças. Porém, agora com a utilização da Impressora 3D isso 
não é mais necessário, já que é possível produzir apenas a peça que foi avariada. Este estudo foi desenvolvido em uma empresa de grande porte, mas considera-se que pode ser aplicado em instituições de diferentes portes.

O objetivo da pesquisa em verificar as vantagens da implementação foi atingido e evidenciado nas contas e no tempo gasto para manutenção das peças que também foi diminuído. Custos esses que impactam diretamente no valor dos produtos da companhia e seu futuro lucro.

Com os resultados positivos encontrados é possível afirmar que essa nova revolução tecnológica traz vantagens para manutenção industrial, como menor tempo de reparo e maior disponibilidade de maquinário, economia na compra de peças para reposição e facilidade no manuseio da impressora 3D.

Como futura pesquisa é relevante verificar a implementação da Impressão 3D em outras áreas e se a mesma é capaz de otimizar todos processos existentes em médias e grandes empresas ou se isso ocorre apenas na área de manutenção industrial.

\section{REFERÊNCIAS}

Agência o Globo. (2017). Indústria recorre mais à impressão 3D, e uso da tecnologia cresce 30\%. (2017) Recuperado de: https://epocanegocios.globo.com/Economia/noticia/2017/02/industria-recorre-maisimpressao-3d-e-uso-da-tecnologia-cresce-30.html. Acesso em: 28/mar/2021.

Agopyan, V. Souza, Ubiraci Espinelli Lemes, Paliari, José Carlos, Andrade, Artemária. (1998). Alternativas para a redução do desperdício de materiais nos canteiros de obras. Coletânea Habitare - (vol. 2). Inovação, Gestão da Qualidade \& Produtividade e Disseminação do Conhecimento na Construção Habitacional, 226249, São Paulo. Recuperado de: http://www.habitare.org.br/pdf/publicacoes/arquivos/104.pdf Acesso em: 29/mar/2021.

Borlido, J. (2017). Indústria 4.0 - Aplicação a sistemas de manutenção. Mestrado Integrado em Engenharia Mecânica. Faculdade de Engenharia. Universidade do Porto. Porto. Recuperado de: https://repositorioaberto.up.pt/bitstream/10216/102740/2/181981.pdf Acesso em: 20/set/2020. 
Bruni, A. L., Famá, R. (2009). Gestão de custos e formação de preço: com aplicações na calculadora HP12C e Excel. (5a ed.). 2. reimpr. Ed. Atlas: São Paulo.

Canessa, E., Fonda, C., Zennaro, M. (2013). Low-cost 3D printing: for science, education and sustainable development. Trieste: ICTP Science Dissemination Unit. Recuperado de: http://sdu.ictp.it/3D/book.html Acesso em: 31/mar/2021.

Del Val, J. L. (2016). Industria 4.0: La Transformación Digital De La Industria. Revista Deusto Ingeniería. Número 17, Ano 2016. Bilbao. Recuperado de: http://revistaingenieria.deusto.es/industria-4-0-la-transformacion-digital-de-laindustria/ Acesso em: 20/set/2020.

Duarte, Henrique. (2014). Descubra como surgiu a impressora 3D. Recuperado de: https://www.techtudo.com.br/dicas-e-tutoriais/noticia/2014/04/descubra-comosurgiu-impressora-3d.html Acesso em: 20/set/2020.

Eduardo G., Ricardo D., Bruno R., José S., Fabrício D., Eduardo S., Walter J., Fabio B. (2018). Use of 3D Printing in Preoperative Planning and Training for Aortic Endovascular Repair and Aortic Valve Disease. Recuperado de: https://www.scielo.br/scielo.php?script=sci_arttext\&pid=S0102-76382018000500490 Acesso em: 29/mar/2021.

Engeman. Indicadores de Manutenção. Recuperado de: https://blog.engeman.com.br/indicadores-de-manutencao Acesso em: 25/ago/2019.

Gorni, A. (2003) Introdução à Prototipagem rápida e seus processos. Recuperado de: http://www.gorni.eng.br/protrap.html. Acesso em: 20/set/2020.

Groover, M. P. (2007). Fundamentals of modern manufacturing: materials processes, and systems. New Jersey: John Wiley \& Sons, 4th Edition.

Governo do Estado de São Paulo. (2019). Resumo Executivo de Energia Elétrica. Recuperado de: http://dadosenergeticos.energia.sp.gov.br/portalcev2/intranet/BiblioVirtual/eletrica/R esumo_Executivo_EE.pdf Acesso em: 20/set/2020.

Hammer, C., Kostroch, D., Quiros, G. (2017). Big Data: Potential, Challenges and Statistical Implications. International Monetary Fund. Recuperado de: https://www.imf.org/en/Publications/Staff-Discussion-Notes/lssues/2017/09/13/BigData-Potential-Challenges-and-Statistical-Implications-45106 Acesso em: 20/set/2020. 
Hausman, K. K., Horne, R. (2014). 3D printing for dummies. Hoboken; New Jersey: John Wiley \& Sons.

Jaebum S., Diana V., María G., Paola C. (2017) An Update on Orthopedic Applications Using 3-Dimensional Printing Technologies, Revista Ingeniería Biomédic. Recuperado de: https://revistas.eia.edu.co/index.php/BME/article/view/1079/1208 Acesso em: 29/mar/2021.

Kardec, A., Nascif, J. (2001). Manutenção função estratégica. Ed. Qualitymark: Rio de Janeiro.

Kormann, R. B., Morschbacher, R., Moreira, H, Akaishi, P. (2019). A three-dimensional printed photopolymer resin implant for orbital rehabilitation for evisceration. Arq. Bras. Oftalmol., São Paulo. Recuperado de: http://www.scielo.br/scielo.php?script=sci_arttext\&pid=S0004$27492019005011109 \&$ Ing=en\&nrm=iso. Acesso em 29/set/2020.

Manda V. R., Kampurath V., Msrk C. (2018). 3D Printing and its Effect on Outsourcing A Study of the Indian Aircraft Industry. Recuperado de: http://www.jatm.com.br/ojs/index.php/jatm/article/view/862_Acesso em: 29/mar/2021.

Martins, E. (1998). Os desafios da controladoria e contabilidade estratégica. Anefac, São Paulo, no 7, p. 8, jul.

Moro, N., Auras, A. P. (2007). Introdução a gestão da manutenção. Florianópolis, SC. Monografia de curso técnico de mecânica industrial._Centro Federal de Educação

Tecnológica de Santa Catarina, Florianópolis. Recuperado de: http://norbertocefetsc.pro.br/downloads/manutencao.pdf. Acesso em: 29/set/2020.

Oliveira, L. M., Perez Jr, J. H., Silva, C. A. S. (2015). Controladoria Estratégica. (11a ed.). Ed. Atlas: São Paulo.

Pesquisa FAPESP. O avanço da impressão 3D (2019). Recuperado de: https://revistapesquisa.fapesp.br/o-avanco-da-impressao-3d Acesso em: 30/mar/2021.

Pinheiro, M. J. S. (2007). O uso da contabilidade de custos no processo de gestão das empresas prestadoras de serviços contábeis. (Dissertação de Mestrado). Universidade Federal do Ceará, UFC, Fortaleza. Brasil. Recuperado de: http://www.repositorio.ufc.br/bitstream/riufc/21416/1/2007_dis_mjspinheiro.pdf. Acesso em: 29/mar/2020. 
Porter, M. E. (1986). Estratégia competitiva. Trad. de Elizabeth M.P. Braga. Rio de Janeiro: Campus.

Roblek, V., Mesko M., Krapez, A. (2016). A Complex View of Industry 4.0. Volume: 6 issue: 2. SAGE Open. Recuperado de: https://doi.org/10.1177/2158244016653987. Acesso em: 29/set/2020.

Rocha, W. (1999). Gestão estratégica. Congresso Brasileiro de Custos. São Paulo, SP, 6. Recuperado de: https://anaiscbc.emnuvens.com.br/anais/article/view/3215 Acesso em: 29/mar/2021.

Silva, S. (2017). Integração e adaptação do SAP e Indústria 4.0 na área de manutenção industrial no Grupo Bosch Termotecnologia, S.A. In RIA - Repositório Institucional da Universidade de Aveiro. Recuperado de: https://www.rcaap.pt/detail.jsp?id=oai:ria.ua.pt:10773/23362. Acesso em: 29/set/2020.

Trajano, B. B., Welter, L. M., Souza, Â. R., Schmidt, P. (2018). Gestão Estratégica de Custos em Entidade De Previdência Complementar Fechada. Revista IberoAmericana de Estratégia - RIAE. Vol. 17, N.2. Abril/Junho. Recuperado de: https://periodicos.uninove.br/riae/article/view/10251/4911Acesso em: 28/mar/2021.

Vaz, J. C. (1998). Gestão da manutenção. In: Contador, J. C. Gestão de operações: a engenharia de produção a serviço da modernização da empresa. (2a ed.). São Paulo: Edgard Blücher.

Vizzotto, M. J., Motta, M. E. V. da, \& Camargo, M. E. (2019). Impacto da gestão estratégica de custos no desempenho econômico-financeiro. Revista Contemporânea De Contabilidade, 16(40), 190-208. Recuperado de: http://doi.org/10.5007/2175-8069.2019v16n40p190

Yang, L. (2017). Industry 4.0: A Survey on Technologies, Applications and Open Research issues. Journal of Industrial Information Integration. Volume 6 , junho de 2017 , páginas 1-10. Recuperado de: https://doi.org/10.1016/j.jii.2017.04.005 Acesso em: 29/set/2020.

Data de Submissão: 28/09/2020

Data de Aceite: 09/04/2021 